\title{
Primary generalised epileptic myoclonus: a frequent manifestation of minipolymyoclonus of central origin
}

\author{
DE WILKINS, ${ }^{*}$ M HALLETT, G ERBA
}

From the Section of Neurology, Department of Medicine, Brigham and Women's Hospital, the Department of Neurology, Children's Hospital Medical Center, and the Department of Neurology, Harvard Medical School, Boston, MA, USA

SUMMARY A group of patients with myoclonus is described whose jerks are preceded by a bilaterally synchronous, frontocentrally predominant, negative cerebral potential in the EEG. This potential may be a slow wave with variable timing in relation to EMG bursts, and in this circumstance the muscle jerks are usually small amplitude and multifocal ("minipolymyoclonus"). The cerebral negativity can also be shorter in duration and time-locked to limb jerks, which are larger in amplitude and more widespread. We propose that the physiology of this distinct form of myoclonus is similar to that of primary generalised epilepsy.

Myoclonus has been recognised in association with bilaterally synchronous discharges as recorded by scalp EEG. These paroxysmal discharges may assume a variety of forms: the regular $3 \mathrm{~Hz}$ spikewave activity of classic petit mal;' atypical, slower spike-wave paroxysms; ${ }^{23}$ diffuse spiking, spikewave, or polyspike wave as seen in myoclonic epilepsies or numerous encephalopathies; ${ }^{45}$ generalised, individual small amplitude "spikes"; 6 rapid 30 $\mathrm{Hz}$ central sinusoidal rhythms; ${ }^{5}$ or the more continuous rhythmic delta activity of a generalised cerebral disturbance. ${ }^{7}$ Recently, the categorisation of myoclonus into electrophysiological types ${ }^{68-12}$ has been facilitated by computerised methodology involving jerk-locked averaging of EEG data..$^{13} \mathrm{We}$ now report a series of patients whose myoclonus was associated with a bilaterally synchronous electrocerebral event.

\section{Methods}

Eleven patients with myoclonus in the setting of different

Presented in part at the thirty-fifth annual meeting of the American Academy of Neurology, San Diego, CA, April, 1983.

*Current address: Division of Neurology, St Vincent's Hospital, Worcester, MA 01604, USA.

Present address and address for reprint requests: Dr Hallett, Clinical Director, NINCDS, Building 10, Room 5N226, NIH, Bethesda, MD. 20205. Telephone: 301-496-1561.

Received 2 July 1984 and in revised form 20 October 1984. Accepted 3 November 1984 chronic epileptic/myoclonic disorders were selected for the purposes of this report on the basis of similarity of their jerk-locked EEG data (table 1). Six patients conformed to the clinical picture of the atypical spike-wave syndrome of Lennox and Gastaut; ${ }^{23}$ two of this group had additional major signs of perinatal encephalopathy (cerebral palsy), and a third had a left temporal lobectomy for a chronic encephalitis. ${ }^{14}$ The seventh and eighth patients carried the clinical diagnosis of Alzheimer's Disease, one in its classic form $^{15}$ and the other in the well-described setting of Trisomy 21 (Down's syndrome). ${ }^{16-18}$ The ninth patient was a 14-year-old girl with a familial progressive myoclonic epilepsy. The tenth patient had a degenerative disease of unknown nature. The last patient had typical petit mal epilepsy with $3 \mathrm{~Hz}$ spike and wave paroxysms on EEG and a strong family history. All patients were taking at least one anticonvulsant agent.

EMG was recorded with pairs of surface electrodes placed longitudinally, $2-3 \mathrm{~cm}$ apart, over the mid-portion of the muscle. EEG was recorded with a Grass Model-8 electroencephalograph in referential linkage to ipsilateral ears with gold cup electrodes positioned in accordance with the 10-20 system (fig 1 ); the frequency response range was 1 to 35 or $70 \mathrm{~Hz}$. The electrical signals were amplified and led to a PDP-11 computer which collected and sometimes averaged the data. Four to sixteen simultaneous data channels were employed. Computer collection was triggered by an event in one of the channels (using a Schmidt trigger pulse); events before and after the trigger could be recorded. The sensitivity of the trigger was set so that a trigger occurred only with definite jerks and not with occasional low level background EMG activity; by doing this, small jerks would not trigger a collection. Topographic analysis of 16-channel EEG data was carried out with computer programs previously described. ${ }^{19}$ 
Table 1 Clinical and EMG data

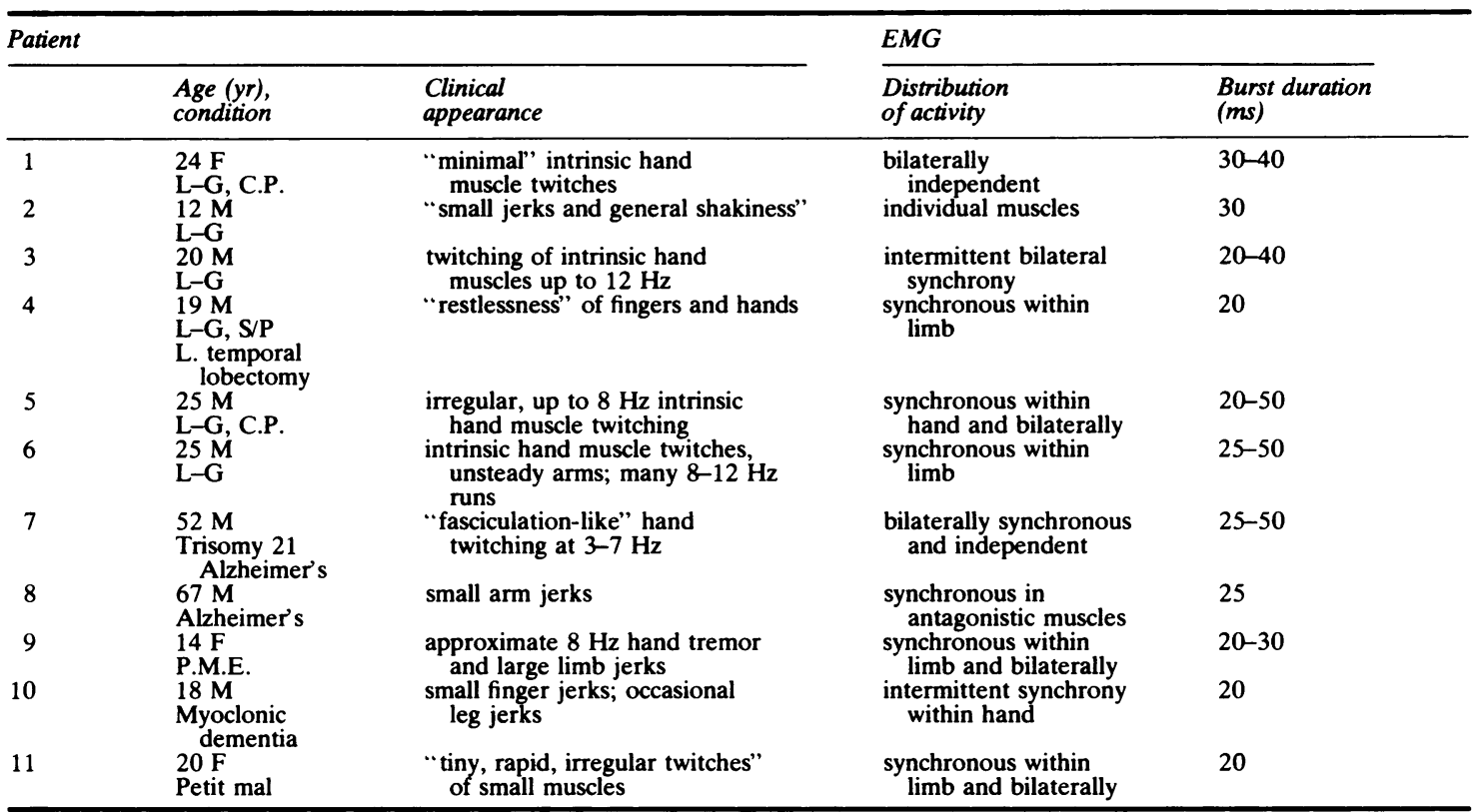

L-G = Lennox Gastaut Syndrome.

C.P. $=$ cerebral palsy.

P.M.E. = progressive myoclonic epilepsy.

$\mathrm{S} / \mathrm{P}=$ status post. Front

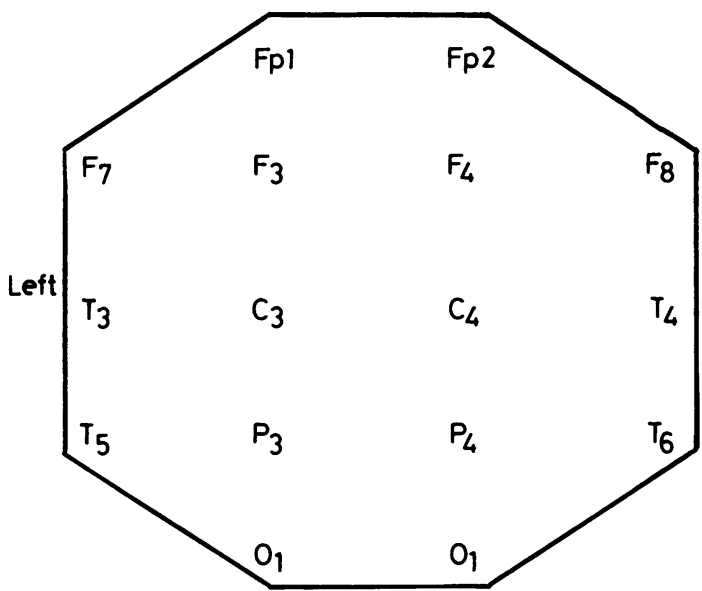

Fig 1 Electrode sites utilised for EEG recording with their positions on the topographic map.

\section{Results}

Clinically, nine patients manifested small, seemingly random, recurring twitches most evident in the fingers and hands. Facial activity, especially repetitive blinking, while present on a number of occasions, was not an invariable accompaniment; leg movements in this group were infrequent. Clinicians had described these minor hand movements as a tremulousness or shakiness; more colourful notations included "minimal myoclonus" and "a fasciculation-like twitching" or "a subtle restlessness" of the fingers. The phenomenon was a bilateral one with only minor, if any, asymmetries. The involuntary movements were present at rest; in some subjects goal-directed movement and stretch enhanced the tremulousness, but it was not possible to study systematically the effects of these manoeuvers. Patients were usually alert; infrequent periods of stupor occurred. Whenever clinical and electroencephalographic drowsiness ensued, if epileptiform discharges persisted, the myoclonus would also persist. Patients 8 and 9 had larger limb jerks with a predilection for the arms. While often serial and occasionally small in amplitude these jerks were clearly more prominent and different from the minor twitching noted above.

EMG activity was best recorded from intrinsic hand muscles or flexor and extensor muscles in the forearm. EMG burst durations were uniformly 10-50 ms. (table 1) The bursts might be confined to individual muscles but often discharged simultaneously in antagonist pairs or in other muscles of the same limb. In addition, bilateral synchrony of homologous muscles was frequently found (fig 2). In half of the subjects EMG bursts were recorded in rapid, sequential patterns (fig $2 \mathrm{~B}$ and $\mathrm{C}$ ), thus generating the clinical impression of tremulousness. These serial EMG discharges could be rhythmic or 
Table 2 EEG data

\begin{tabular}{|c|c|c|c|c|c|}
\hline & \multicolumn{2}{|l|}{$E E G$} & \multicolumn{3}{|l|}{ Jerk-locked EEG } \\
\hline & $\begin{array}{l}\text { Back- } \\
\text { ground }\end{array}$ & $\begin{array}{l}\text { Special } \\
\text { features }\end{array}$ & $\begin{array}{l}\text { Distribution } \\
\text { of potential }\end{array}$ & $\begin{array}{l}\text { Onset of potential } \\
\text { (ms pre-jerk) }\end{array}$ & $\begin{array}{l}\text { Duration of } \\
\text { potential (ms) }\end{array}$ \\
\hline 1 & $\begin{array}{l}\text { theta, } \\
\text { delta }\end{array}$ & $\begin{array}{l}\text { atypical } 1 \cdot 5-2 \mathrm{~Hz} \\
\text { spike-wave }\end{array}$ & $\begin{array}{l}\text { bifrontal } \\
\text { negativity }\end{array}$ & 160 & 100 \\
\hline 2 & $\begin{array}{l}\text { theta, } \\
\text { delta }\end{array}$ & $\begin{array}{l}\text { atypical } 2 \mathrm{~Hz} \\
\text { spike-wave, } \mathrm{L}>\mathrm{R}\end{array}$ & $\begin{array}{l}\text { bifrontocentral } \\
\text { negativity }\end{array}$ & 125 & 200 \\
\hline 3 & theta & $\begin{array}{l}\text { typical and atypical } \\
3 \mathrm{~Hz} \text { spike-wave, } \\
\text { prominent } 7-8 \mathrm{~Hz} \\
\text { bifrontal rhythm }\end{array}$ & $\begin{array}{l}\text { bifrontocentral } \\
\text { negativity; time- } \\
\text { locked; same as the } \\
7-8 \mathrm{~Hz} \text { rhythm }\end{array}$ & $40-60$ & $40-60$ \\
\hline 4 & theta & $\begin{array}{l}\text { atypical } 2.5 \mathrm{~Hz} \text { spike- } \\
\text { wave }\end{array}$ & $\begin{array}{l}\mathrm{R}>\mathrm{L} \text { bifrontal } \\
\text { negativity }\end{array}$ & $\begin{array}{l}\text { singles } \\
\quad \text { jittered; } \\
\text { average } 160\end{array}$ & 100 \\
\hline 5 & theta & $\begin{array}{l}\text { atypical } 3.5 \mathrm{~Hz} \\
\text { spike-wave }\end{array}$ & $\begin{array}{l}\text { bifrontocentral } \\
\text { negativity; same } \\
\text { from each arm }\end{array}$ & $\begin{array}{l}\text { singles } \\
\text { jittered; } \\
\text { average } 160\end{array}$ & 160 \\
\hline 6 & theta & $\begin{array}{l}\text { atypical } 2 \mathrm{~Hz} \text { spike- } \\
\text { wave; L. temporal focus }\end{array}$ & $\begin{array}{l}\text { bifrontal } \\
\text { negativity }\end{array}$ & $\begin{array}{l}\text { singles } \\
\text { jittered; } \\
\text { average } 250\end{array}$ & 250 \\
\hline 7 & theta & $\begin{array}{l}\text { frequent } 4 \mathrm{~Hz} \text { bifrontal } \\
\text { rhythm with intermixed } \\
\text { sharp waves }\end{array}$ & $\begin{array}{l}\text { bifrontal } \\
\text { negativity; time- } \\
\text { locked; same from each arm }\end{array}$ & 50 & 100 \\
\hline 8 & $\begin{array}{l}\text { diffuse } \\
4-5 \mathrm{~Hz} \\
\text { theta }\end{array}$ & $\begin{array}{l}\text { theta of largest } \\
\text { amplitude bifrontally }\end{array}$ & $\begin{array}{l}\text { bifrontal negativity; } \\
\text { time-locked }\end{array}$ & 170 & 180 \\
\hline 9 & $\begin{array}{l}9 \mathrm{~Hz} \\
\text { alpha }\end{array}$ & $\begin{array}{l}\text { bifrontal spike-wave, } \\
\text { i.e. } 16 \mathrm{~Hz} \text { beta with } \\
\text { theta }\end{array}$ & $\begin{array}{l}\text { bifrontal negativity; } \\
\text { time-locked; same } \\
\text { from each arm; same } \\
\text { as } 16 \mathrm{~Hz} \text { beta }\end{array}$ & 40 & 30 \\
\hline 10 & $\begin{array}{l}\text { theta, } \\
\text { delta }\end{array}$ & $\begin{array}{l}\text { bifrontal rhythmic } \\
\text { delta, intermixed } \\
\text { spikes/polyspikes }\end{array}$ & $\begin{array}{l}\text { bifrontocentral } \\
\text { negativity }\end{array}$ & $\begin{array}{l}\text { singles } \\
\quad \text { jittered; } \\
\text { average } 250\end{array}$ & 250 \\
\hline 11 & $\begin{array}{l}8 \mathrm{~Hz} \\
\text { alpha }\end{array}$ & $\begin{array}{l}\text { typical } 3 \mathrm{~Hz} \\
\text { spike-wave }\end{array}$ & $\begin{array}{l}\text { bifrontocentral } \\
\text { negativity }\end{array}$ & $10-50$ & 150 \\
\hline
\end{tabular}

irregular within a $1-12 \mathrm{~Hz}$ frequency range.

Routine 16-channel EEGs demonstrated the absence of alpha and diffuse theta activity in nine patients. Additional slowing in the delta range was contained in seven records as part of spike-wave complexes. (table 2) Simultaneous recording of EMG and routine EEG activity was only performed in two instances during which a coarse correlation was sometimes observed between frontal paroxysmal activity and the muscular events (fig 3).

Back-averaging the EEG from single myoclonic twitches or from series of 10-48 twitches revealed in all cases a bifrontal or bifrontocentral negative cerebral potential in association with the muscular myoclonic activity. In six patients consecutive series of individual jerk-locked EEG tracings were examined: in most subjects a cerebral negativity was seen in $50-100 \%$ of the sequential single tracings in a form similar to if not identical with the EEG potential obtained by averaging from a larger series of jerks. Closer inspection of the jerk-locked EEG data revealed two distinct types of bifrontal/ bifrontocentral cerebral negativity differentiating patients otherwise indistinguishable by clinical and electromyographic criteria. The first jerk-locked pattern occurred in seven patients (numbers $1,2,4$,
$5,6,10,11)$ as a bifrontal/bifrontocentral cerebral negativity of relativity long average duration (100$250 \mathrm{~ms})$ and of variable pre-jerk onset $(5-500 \mathrm{~ms})$ (fig 4). Although this range of pre-jerk onsets was considerable when single tracings from the entire subgroup were tabulated, individual subjects demonstrated a narrower range of onsets varying less than $250 \mathrm{~ms}$. The second pattern exhibited by four patients (numbers $3,7,8,9$ ) consisted of an invariant cerebral potential time-locked to the jerks. In three of these four subjects the bifrontal negativity was of relatively short duration $(30-100 \mathrm{~ms}$ range, although fixed for each individual subject) and stereotyped onset (40-60 ms pre-jerk) (fig 5). This short duration negativity correlated with bifrontal spikes in the routine EEG in one instance (patient 9) and with a remarkable $8 \mathrm{~Hz}$ bifrontal cerebral rhythm was in another (patient 3), (fig 6). In the other two patients (numbers 7,8 ) it was not possible to distinguish the correlate of the jerklocked potential from the routine EEG background. Since the major feature of all of the above data was a bifrontal electrical event, eye movement artifacts were controlled for in a detailed manner in four patients and were found not to be involved in the genesis of the jerk-locked cerebral potentials (fig 7). 

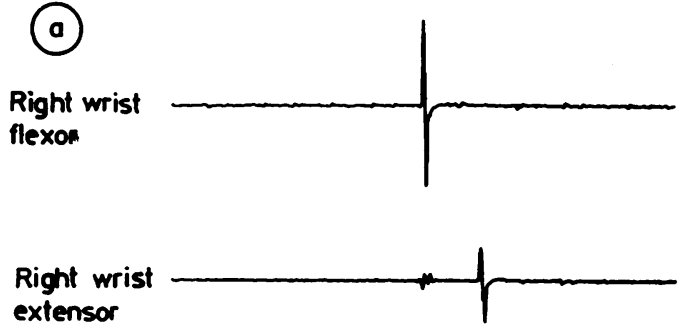

(b)

Right FDI
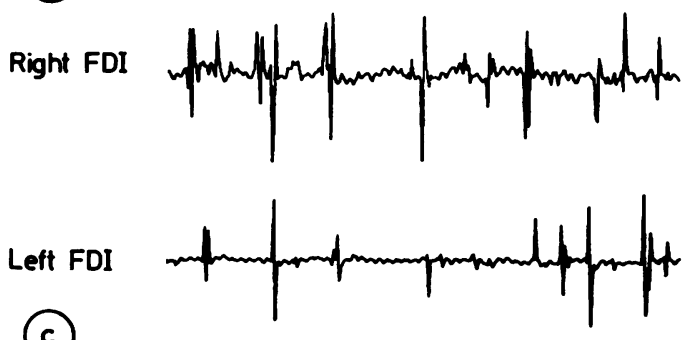

(c)

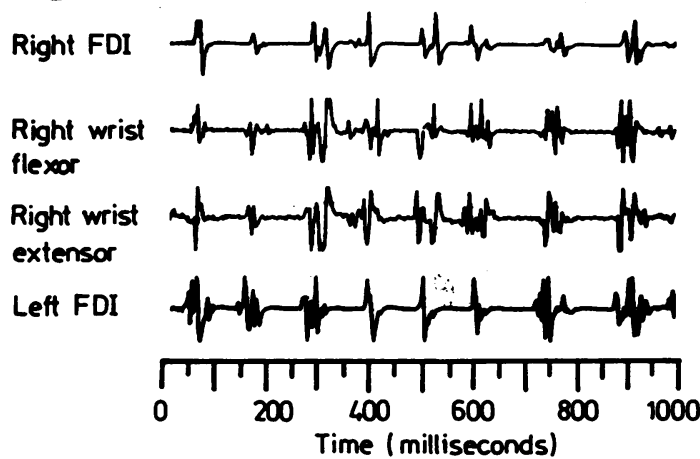

Fig 2 Patterns of EMG activity underlying the myoclonus in three different patients. Part $A$ is from patient 8 , part $B$ from patient 6 , and part $C$ from patient $5 . F D I=$ first dorsal interosseus.

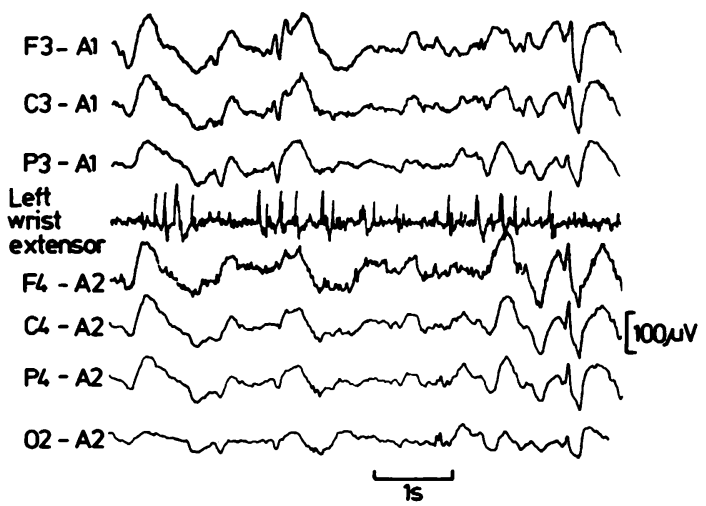

Fig 3 Simultaneous EEG and EMG recording showing loose correlation between cerebral slow waves and myoclonic jerks. Record from patient 6.
In three subjects representing both those with the minor twitches and the subgroup with the larger jerks jerk-locked recording was performed from right and left arms; in every case the same bifrontocentral negative potential was generated.

Myoclonic jerks in patient 9 involved cranial nerve muscles. Simultaneous recording of orbicularis oculi and sternocleidomastoid showed that the former muscle always preceded the latter muscle when they were both active in the same jerk (fig 8).

\section{Discussion}

The computerised technique of jerk-locked EEG analysis has now documented the association of myoclonus with a bilaterally synchronous EEG event. Although in these patients the myoclonic jerks were not generalised, they were often bilaterally synchronous. This bilateral simultaneity, which can be appreciated only by EMG, separates this type of myoclonus from multifocal cortical myoclonus and, by itself, is indicative of bilateral simultaneous central nervous system activation. Bilateral myoclonus resulting from transcallosal transmission has a $10 \mathrm{~ms}$ asynchrony and a distinctive EEG correlate. $^{812}$ The bilaterally synchronous frontocentral cerebral potentials appear to represent true bilateral synchrony and can be categorised into two patterns.

The first pattern was that of a slow bifrontocentral negativity whose onset jittered in relation to the myoclonic EMG discharges. Our study is not the first to detect a loose but recurring relationship between slow cerebral potential and myoclonic jerks; we have chosen to emphasise this relationship, however, whereas earlier reports tended to ignore the slow waves while concentrating upon the spikes. Some previous reports have shown that the slow wave component of spike-wave discharges can, in fact, be associated with inhibition of muscle activity. ${ }^{2021}$ Other studies, however, offer supportive evidence for our findings. In fig 2C of Grinker et al ${ }^{22}$ myoclonic EMG bursts occur just as frequently in association with $250 \mathrm{~ms}$ slow waves as with EEG spikes. In fig $4 \mathrm{C}$ of Jasper and Andrews' a persistent myoclonic EMG discharge at $4.7 \mathrm{~Hz}$ is aligned with a simultaneous $2.6 \mathrm{~Hz}$ spike-wave cerebral rhythm resulting in an obvious, frequent but not timelocked overlapping of slow waves and EMG bursts. Dawson $^{4}$ also observed: "In the wave and spike seizure the muscle action potential. . . may actually precede the earliest recognisable phase of the EEG spike. This suggests that in the wave and spike seizure the efferent discharge giving rise to the muscular activity is not a direct correlate of the EEG spike...." Dawson never commented upon the 
(a)
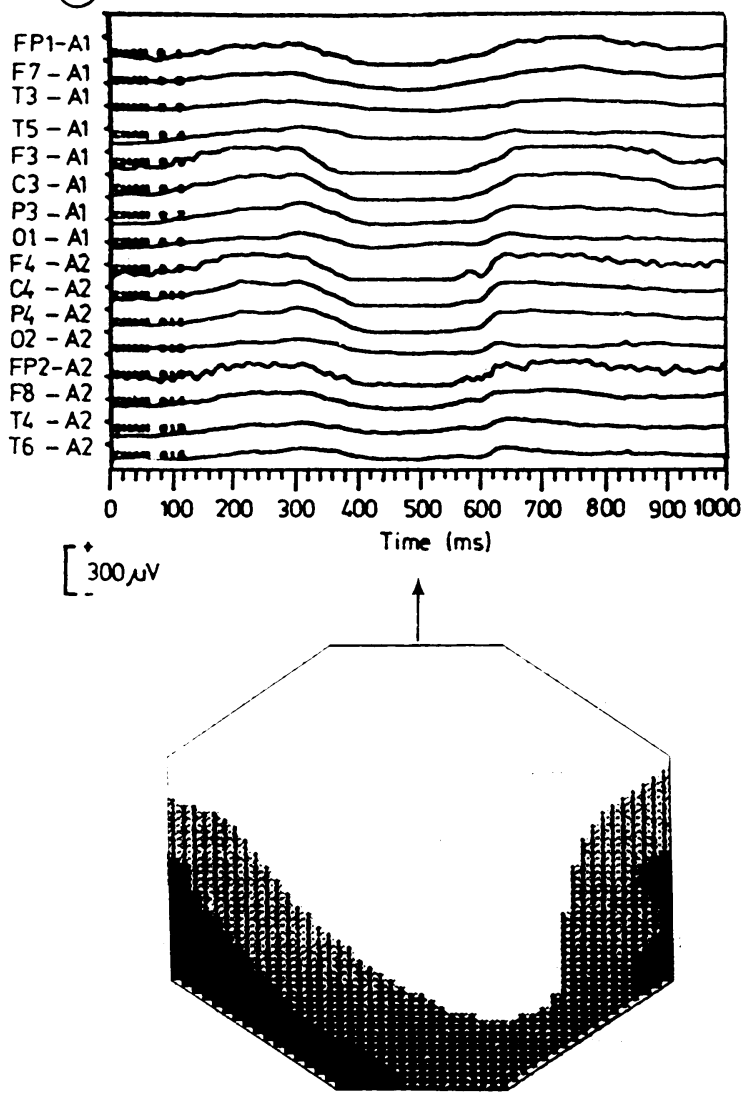

(b)
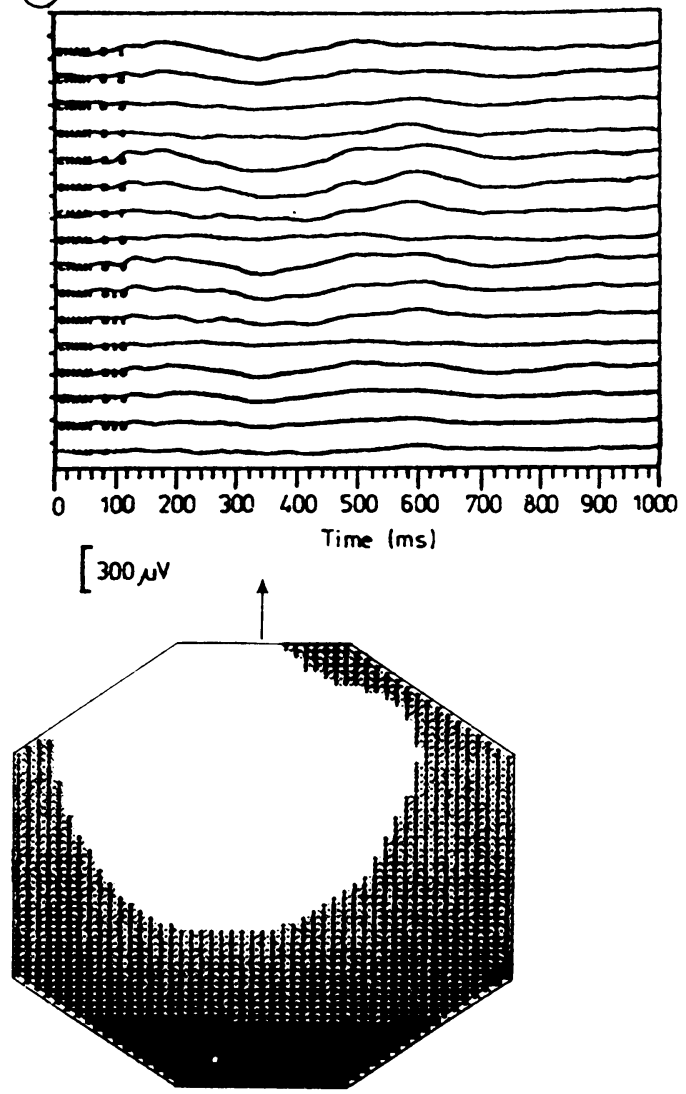

Fig 4 EEG activity time-locked to myoclonic jerks which have occurred at $500 \mathrm{~ms}$. a, b and c are single events showing variability of timing of cerebral slow wave with respect to the jerk; $d$ is an average of 34 consecutive recorded EEG segments. Topographic map plotted from the EEG at the time of the arrow shows the distribution of the negativity. Recordings are from patient 6.

relationship of the slow waves to the jerks, but this was unmistakably, if unintentionally, implied. Even Gastaut et al before his correlation of muscular inhibition with slow waves had commented during the course of a careful analysis of syncope: ". . . slow bilateral large amplitude delta waves reappear, often accompanied by a myoclonic jerk or two. ..."

A second type of jerk-locked EEG potential, also negative and bifrontocentral in distribution but shorter in duration than the first, was time-locked to the myoclonic jerks. Both minor finger/hand twitches and larger limb jerks were associated with this pattern of cerebral activity. Myoclonic jerks have been previously closely linked to antecedent focal, lateralised cerebral events, but a time-locked bifrontocentral potential has not been described. Even in our single case of a progressive myoclonic epilepsy syndrome where we anticipated a contralateral, focal jerk-locked EEG event similar to that reported by Shibasaki et $a^{8}$ a bifrontocentral cerebral negativity time-locked to the jerks was demonstrated (fig 5).

The anatomy and physiology responsible for this type of myoclonus is not immediately apparent. One possibility is that there is a cerebral focus to which the scalp EEG is blind which has rapid access to bilateral pathways. ${ }^{23}$ More likely is that the pathophysiological process is the same as that of primary generalised epilepsy, a disorder which at least eight of the eleven patients had by routine clinical and EEG criteria. Unfortunately, this process is not well understood. A contemporary view is that the abnormality lies in the ascending activating pathways between the brainstem reticular formation 
(c)
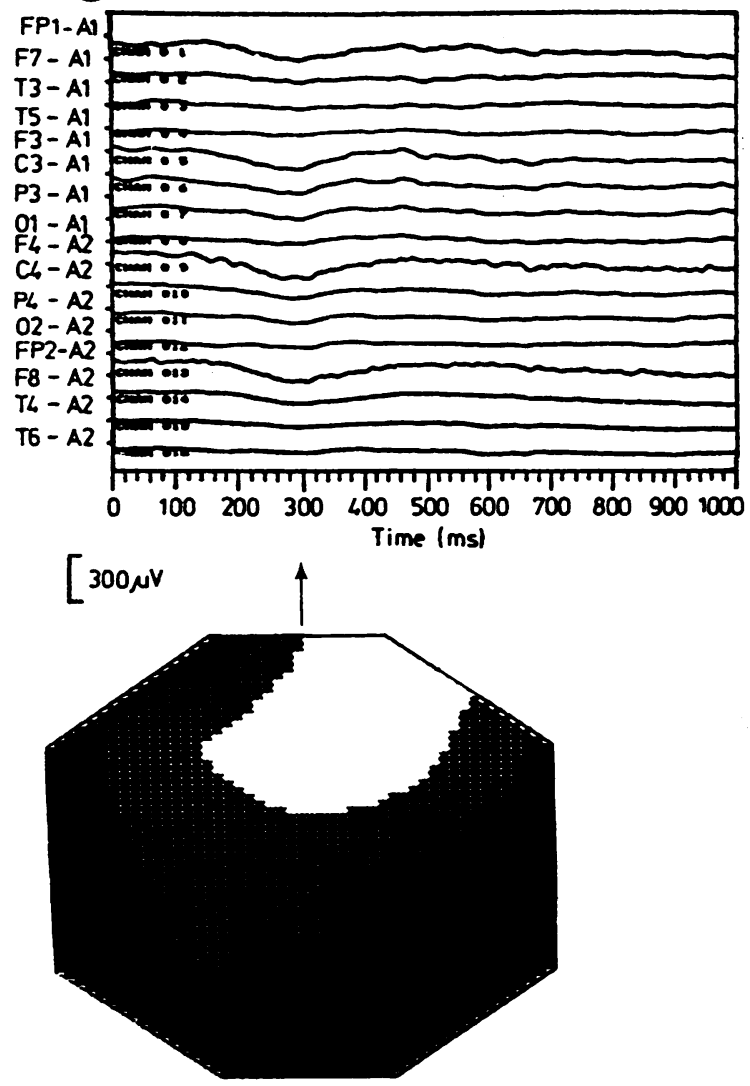

and non-specific thalamic nuclei (which make up the "centrencephalon") and the cerebral cortex..$^{24}{ }^{25}$ The abnormal discharge could arise subcortically and disturb the function and electrical activity of an otherwise quiescent, non-paroxysmally active cor-

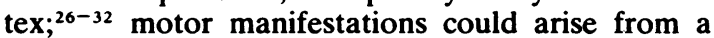
direct spinal projection of the subcortical focus or from the secondary discharge from cortex or both. Alternatively, the subcortical discharges could be normal and the response of the cortex hyperactive; ${ }^{24}$ motor manifestations could arise from a direct effect of cortex or from cortical facilitation of the normal subcortical descending projections. Of course, both subcortical and cortical structures could be abnormal. ${ }^{3}$ Activation of the seventh cranial nerve before the eleventh cranial nerve, as seen in patient 9 , suggests that the origin of the impulse must be at least as cephalad as the pons (putting it higher than the (a)
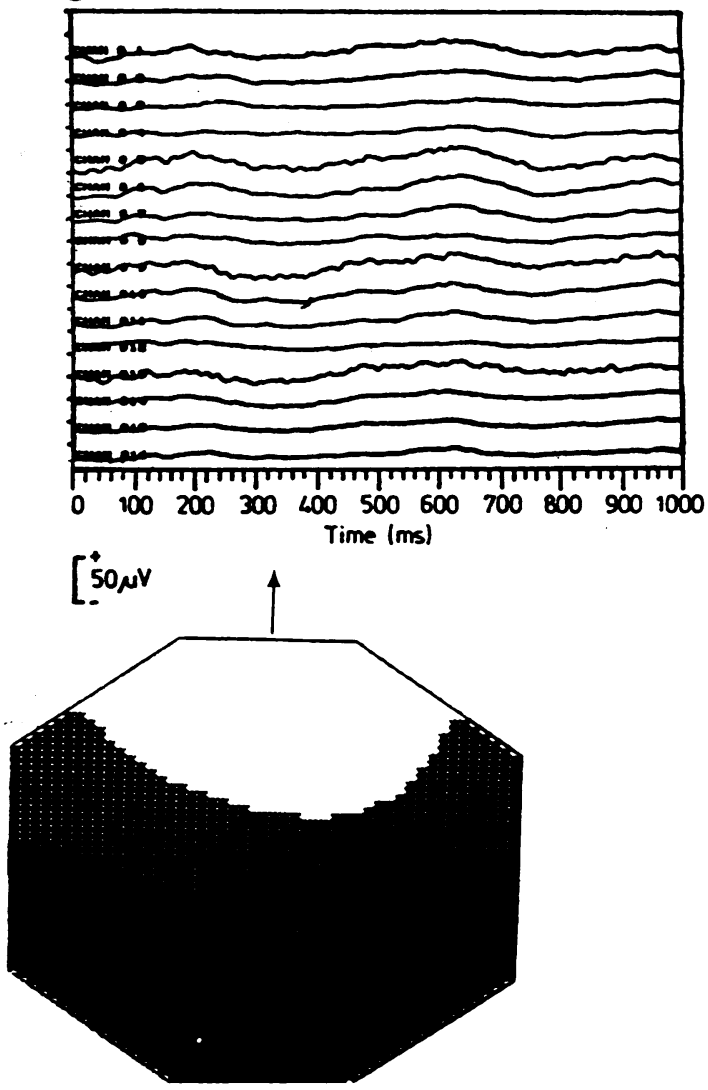

generator of reticular reflex myoclonus).

We are attracted to the primary generalised mechanism because of the EEG topography of the cerebral event correlating with the myoclonic jerk. Stimulation of the non-specific thalamus gives rise to a bilateral frontocentral "recruiting response" of the cortex. $^{34}$ If the cortex is asleep, spindles are produced, and, if it is hyperactive, spike and wave is produced ${ }^{35}$ both patterns have the same bilateral frontocentral topography. The remarkable $8 \mathrm{~Hz}$ pattern in patient 3 might well be identical to a recruiting response (fig 6). In the other cases reported here a hyperactive cortex is probably also important in generating the electrophysiological abnormality. Certainly the cortical event always precedes the myoclonus. This is unlike reticular reflex myoclonus where the abnormal discharge appears to originate in the medullary reticular formation; the EEG spike 
(a)

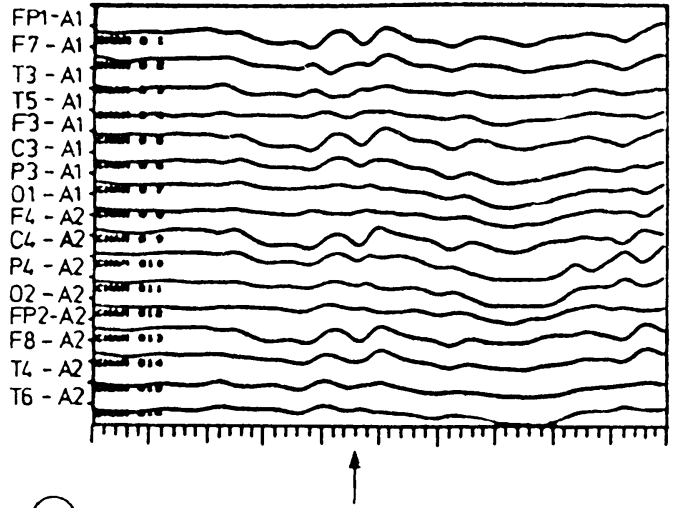

(c)

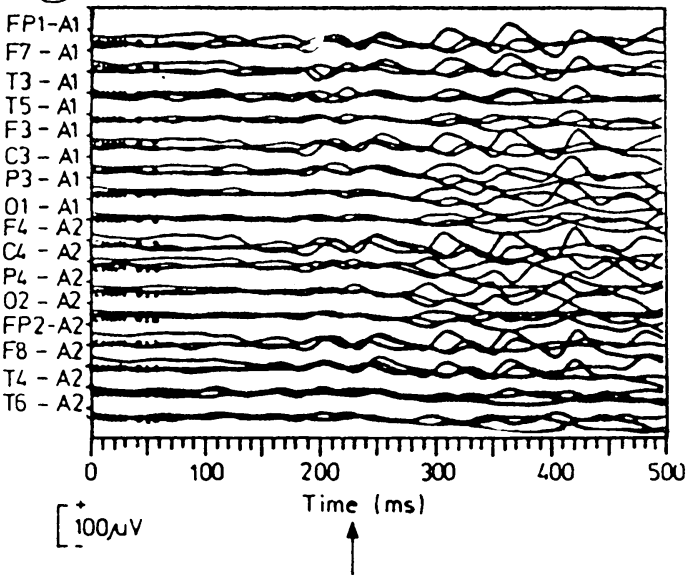

(b)

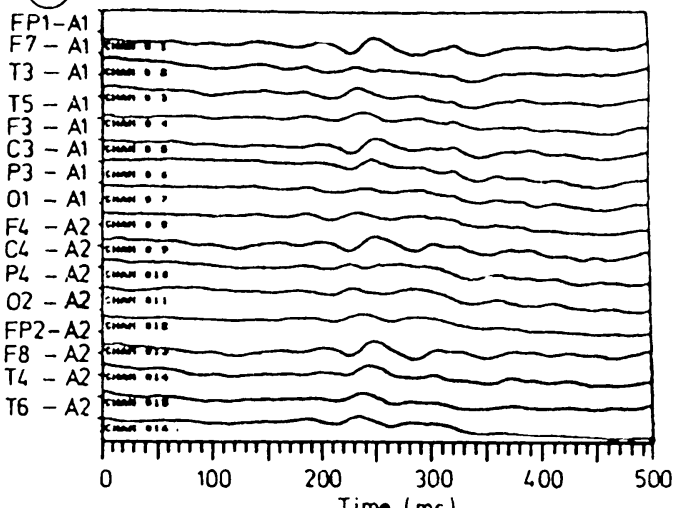

(d)
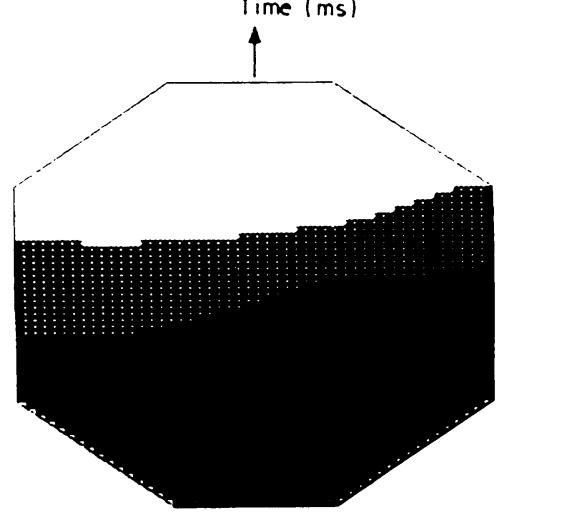

Fig 5 EEG activity time-locked to myoclonic jerks in patient 9 which have occurred at 250 ms. a shows a single event; $b$ shows 3 overlapped single events, and c shows an average of 16 events. Topographic map is plotted from the EEG at the time of the arrow.

appears to reflect the arrival of that discharge at the cerebral cortex but follows the myoclonus in some muscles and seems uninvolved in evoking the myoclonus. ${ }^{\circ}$ On the other hand, the loose coupling between EMG and EEG events in a number of our cases and the bilaterally synchronous EEG event in all clearly differ from the focal, tight coupling of cortical reflex myoclonus. ${ }^{9}$ But how can the cortical slow waves recorded in this study be so closely associated with the myoclonus when slowing has been thought to reflect inhibition. ${ }^{2021}$ The loose coupling suggests the operation of a polysynaptic pathway in which many events could occur including inhibition of inhibition. Myoclonus would arise only when the summed EPSPs in neurons in spinal motor neuron pools exceeded firing threshold; this would account for only a few different muscles firing with each cerebral wave.
Dawson, ${ }^{4}$ in his landmark study attempting to correlate EMG discharges with EEG events, observed that large myoclonic jerks tended to be associated with a brief, time-locked cerebral potential whereas mild muscular twitchings were more loosely associated with spike-wave activity. Though not exact, strong trends in our data support Dawson's notions. In eight of nine subjects slow waves, often part of a spike-wave discharge, loosely co-existed with minor finger/hand twitches. And of the three patients with larger limb jerks two did manifest a time-locked cerebral potential of shorter duration.

The twitching, tremulous fingers and hands frequently referred to throughout this paper are of some interest since they are clinically similar to the "minipolymyoclonus' of Spiro $^{36}$ and the "contraction pesudotremor" of Riggs et al..$^{37}$ Spiro had noted "a peculiar tremulousness" of the outstretched 

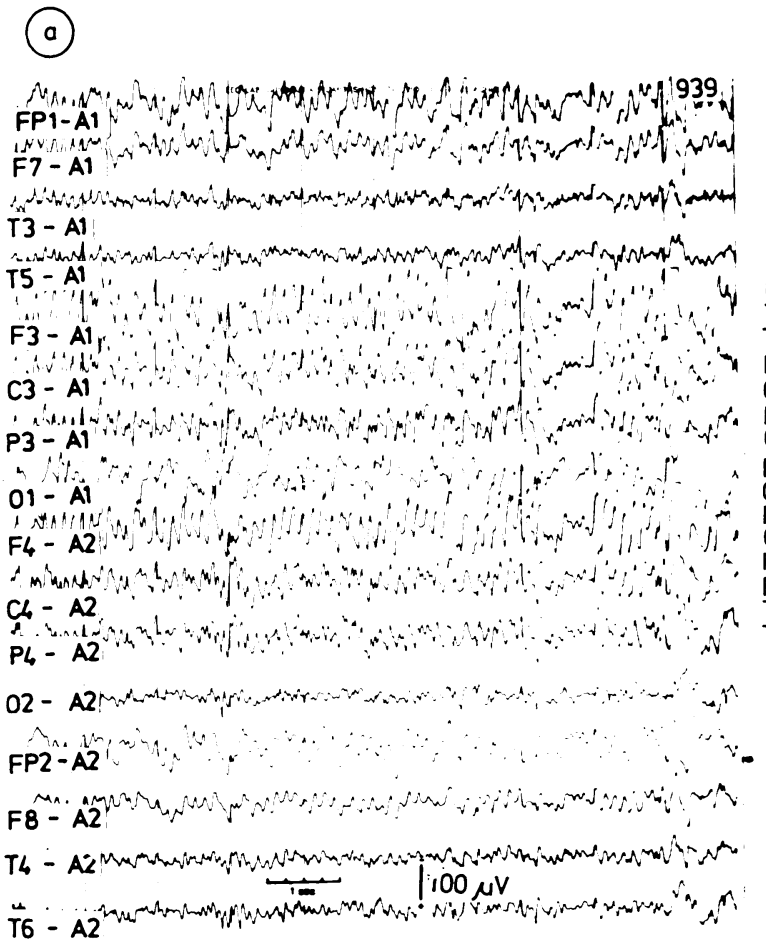

(b)
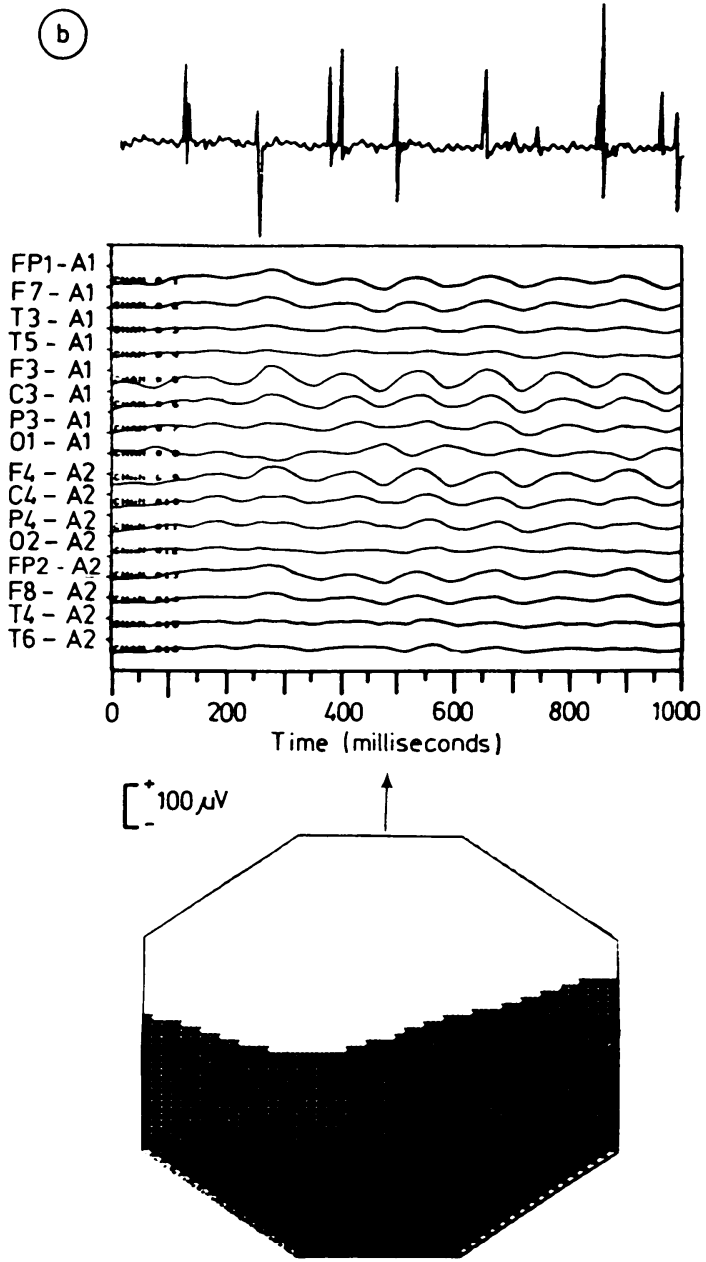

Fig 6 Recordings from patient 3 whilst jerking. a. EEG shows $7-8 \mathrm{~Hz}$ frontal rhythm. $b$ shows a single EMG recording from left first dorsal interosseus, average of 10 EEG segments triggered by jerks occurring at 500 ms and topography at time of arrow.

hands in the setting of juvenile motor neuron disease: "The minipolymyoclonus is characterised by intermittent and irregular movements, with amplitudes just sufficient to produce visible and palpable movements of the joints. ..." The same phenomenon had been recognised by Duchenne in 1883 , and elaborated upon by Denny-Brown and Pennybacker in $1938 .{ }^{3 \times}$ The former had noted that large fasciculations at rest could cause little movements of the fingers, and the latter indicated that a tremor-like wavering of a finger, "a fascicular tremor," could occur with action due to poor fusion of large motor units. That a cerebral epileptic event may also manifest a similar subtle twitching had been recognised since the nineteenth century. Symonds, in a review of myoclonus, ${ }^{34}$ quotes a number of workers from that era among whom Unverricht is most descriptive (1891): "The contraction often produced little movement of the limbs, but caused widespread random twitching. ..." Since the advent of the EEG multiple investigators have correlated these minor muscular movements with cerebral epileptiform discharges. Jasper and Andrews ${ }^{1}$ demonstrated that myoclonic activity in finger extensor and flexor muscles could occur in a fixed, time-locked relationship to an EEG spike or loosely coexist with a spikewave pattern. And Dawson ${ }^{4}$ again observed: " At the start of the prolonged periods of jerking the EEG shows a continuous discharge of slow waves and irregular spikes. This stage is characterised by 
(a)

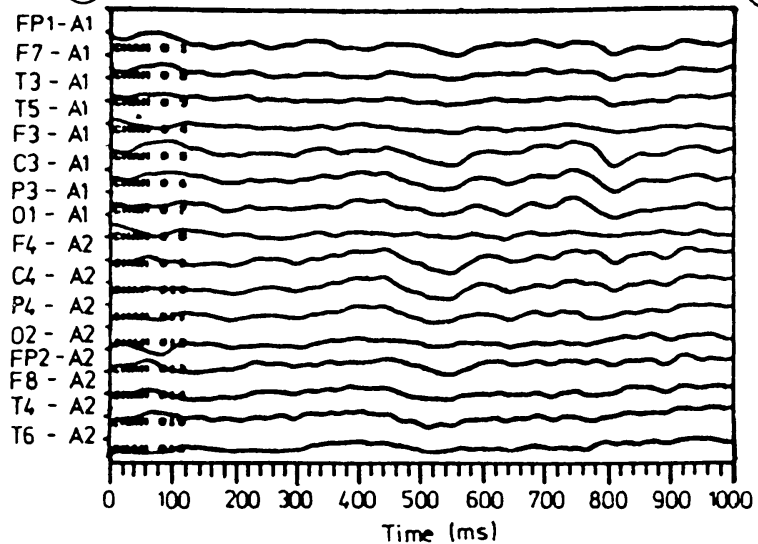

$\left[\begin{array}{ll}+ \\ 100 \mu \mathrm{NV}\end{array}\right.$

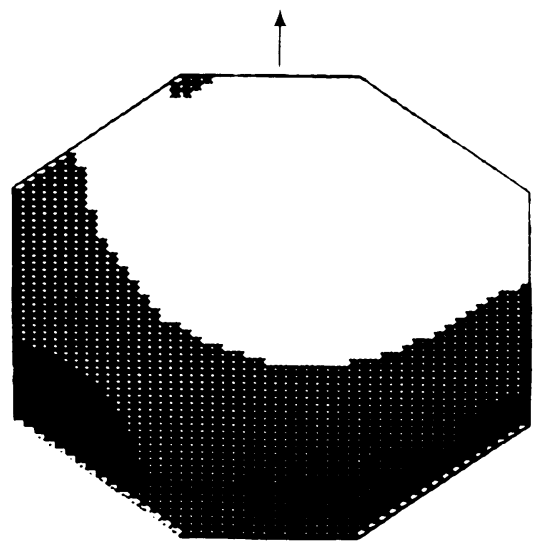

(b)
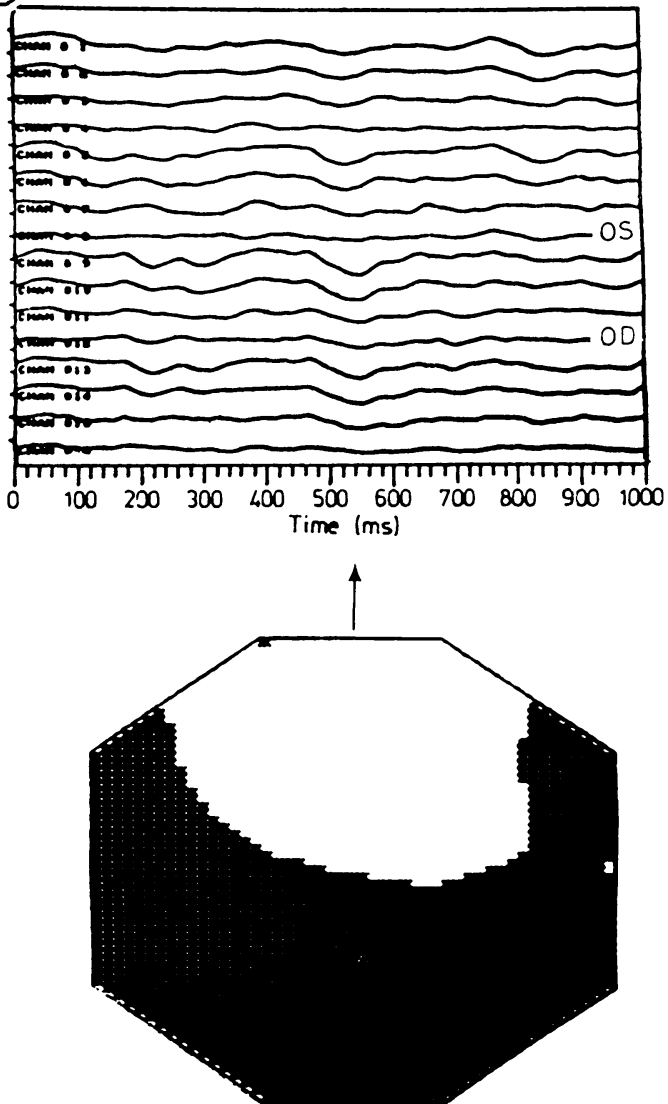

Fig 7 Recording from patient 5 demonstrating that bifrontal negativity is not eye movement artifact. a shows average of 10 EEG events triggered by myoclonic jerk at $500 \mathrm{~ms}$ along with topographic map at time of arrow. $b$ is the same with electrodes below the left and right eyes replacing electrodes at $O_{1}$ and $O_{2}$ (channels 8 and 12) respectively. If the bifrontal negativity (seen clearly in channels 1, 5, 9, and 13) were eye movement artifact, then the eye movement monitors would show corresponding positive deflections.

diffuse and irregular muscular twitching. ..." Additional correlations of small amplitude myoclonic activity, often maximal in the upper extremities, have been made with atypical spike-wave EEG discharges, ${ }^{240}$ classical $3 \mathrm{~Hz}$ petit mal patterns, ${ }^{41}$ and polyspike cerebral electrical activity. ${ }^{42}$

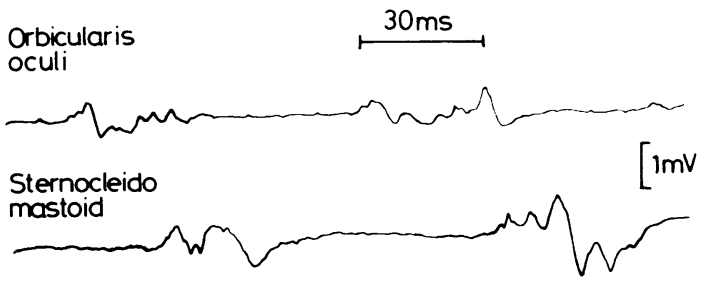

Fig 8 Surface EMG recording from left orbicularis oculi and left sternocleidomastoid from patient 9.
Minipolymyoclonus as a clinical sign, then, is nonspecific (table 3). Both enhanced physiological tremor and essential tremor may generate similar movements. ${ }^{4344}$ Other disorders confined to the central nervous system can mimic minipolymyoclonus. Kinsbourne ${ }^{45}$ reported upon "myoclonic encephalopathy of infants" observing: "at rest, irregular twitching was evident, especially in the fingers, feet, and face." EMG correlates of the movements were not recorded, but routine EEGs were uniformly normal. The same clinical syndrome was later termed "infantile polymyoclonia" by other investigators ${ }^{46}$ further complicating the nomenclature of this clinical sign. Minipolymyoclonus in the present setting of chronic myoclonic/epileptic disorders is characterised by: a subtle twitching predominant in the fingers and hands occurring at rest and 
Table 3 Differential diagnosis of "minipolymyoclonus"

\begin{tabular}{lll}
\hline Clinical setting & $E M G$ & $E E G$ \\
\hline Lower motor neuron "fascicular tremor" & $\begin{array}{l}25-100 \mathrm{~ms} \text { burst durations. } \\
\text { Irregular } 1-20 \mathrm{~Hz} \text { activity. Asynchronous }\end{array}$ & Normal \\
Enhanced physiological and essential tremors & $\begin{array}{l}50-150 \mathrm{~ms} \text { burst durations. } \\
4-12 \mathrm{~Hz} \text { rhythmic activity. } \\
\text { Antagonistic muscles commonly } \\
\text { synchronous. }\end{array}$ & Normal \\
$\begin{array}{l}\text { Unknown } \\
\text { Epileptic myoclonus }\end{array}$ & $\begin{array}{l}\leq 50 \text { ms burst durations. } \\
\text { Regular or irregular 1-12 Hz activity. } \\
\text { Tendency to synchrony in antagonists and } \\
\text { bilaterally. }\end{array}$ & $\begin{array}{l}\text { Normal } \\
\text { Typically epileptiform and usually } \\
\text { correlated to some degree with the } \\
\text { jerks. }\end{array}$ \\
\hline
\end{tabular}

often accentuated by action; the EMG correlate of these movements consists of $20-50 \mathrm{~ms}$ discharges which typically are synchonous within all activated muscles; the twitching is commonly associated with an obvious paroxysmal EEG with additional jerklocked recordings demonstrating associated bifrontal cerebral negativity. Conceivably a multifocal myoclonic disorder may underlie minipolymyoclonus, but we have not yet evaluated such a case. This electrophysiologic profile can be easily differentiated from the other causes of minipolymyoclonus (table 3 ). The fasciculatory manifestations of lower motor neuron disorders lack central synchronisation of multiple muscles and any relationship to electrocerebral events. Enhanced physiological and essential tremors also occur without regard to EEG activity but, additionally, are absent at rest and are generated by EMG discharges $50-150 \mathrm{~ms}$ in duration. ${ }^{44}$ We cannot comment upon the EMG correlate of Kinsbourne's myoclonic encephalopathy since, to our knowledge, this has not been reported; a sufficient distinction can be attained, however, with recognition of the normal EEG.

\section{References}

' Jasper $\mathrm{HH}$, Andrews $\mathrm{HJ}$. Brain potentials and voluntary muscle activity in man. $J$ Neurophysiol 1938;1:87100.

${ }^{2}$ Lennox WG, Davis JP. Clinical correlates of the fast and the slow spike-wave electroencephalogram. Pediatrics 1950;5:626-44.

${ }^{3}$ Gastaut H, Roger J, Soulayrol R, et al. Childhood epileptic encephalopathy with diffuse slow spike-wave (otherwise known as "Petit Mal Variant") or Lennox Syndrome. Epilepsia 1966;7:139-79.

${ }^{4}$ Dawson GD. The relation between the electroencephalogram and muscle action potentials in certain convulsive states. J Neurol Neurosurg Psychiatry 1946;9:522.

${ }^{5}$ Halliday AM. The electrophysiological study of myoclonus in man. Brain 1967;90:241-84.

${ }^{6}$ Hallett M, Chadwick D, Adam J, Marsden CD. Reticular reflex myoclonus: a physiological type of human post-hypoxic myoclonus. $J$ Neurol Neurosurg
Psychiatry 1977;40:253-64:

' Gastaut H, Fisher-Williams M. Electro-encephalographic study of syncope. Lancet 1957;2:1018-25.

${ }^{8}$ Shibasaki H, Yamashita Y, Kuroiwa Y. Electroencephalographic studies of myoclonus. Myoclonus-related cortical spikes and high amplitude somatosensory evoked potentials. Brain 1978;101:447-60.

${ }^{9}$ Hallett M, Chadwick D, Marsden CD. Cortical reflex myoclonus. Neurology (Minneap) 1979;29:1107-25.

${ }^{10}$ Hallett M, Chadwick D, Marsden CD. Ballistic movement overflow myoclonus. Brain 1977;100:299-312.

"Shibasaki H, Motomura S, Yamashita Y, Shii H, Kuroiwa Y. Periodic synchronous discharge and myoclonus in Creutzfeldt-Jakob disease: diagnostic application of jerk-locked averaging method. Ann Neurol 1981;9:150-6.

12 Wilkins DE, Hallett M, Berardelli A, Walshe T, Alvarez N. Physiological analysis of the myoclonus of Alzheimer's Disease. Neurology (NY) 1984;34: 898-903.

${ }^{13}$ Shibasaki H, Kuroiwa Y. Electroencephalographic correlates of myoclonus. Electroencephalogr Clin Neurophysiol 1975;39:455-63.

${ }^{14}$ Aguilar MJ, Rasmussen T. Role of encephalitis in pathogenesis of epilepsy. Arch Neurol 1960;2:66376.

is Sulkava R, Haltia M, Paetau A, Wikstrom J, Palo J. Accuracy of clinical diagnosis in primary degenerative dementia: correlation with neuropathological findings. J Neurol Neurosurg Psychiatry 1983;46:9-13.

${ }^{16}$ Olson MI, Shaw CM. Presenile dementia and Alzheimer's disease in mongolism. Brain 1969;92: 147-56.

17 Malamud N. Neuropathology of organic brain syndromes associated with aging. In: Gaitz GM, ed. Advances in Behavioral Biology. New York: Plenum Press, Inc., 1972;3:63-87.

${ }^{18}$ Ellis WG, McCulloch JR, Corley CL. Presenile dementia in Down's syndrome. Neurology (Minneap) 1974; 24:101-6.

${ }^{19}$ Canter NL, Hallett M, Growden JH. Lecithin does not affect EEG spectral analysis or P300 in Alzheimer disease. Neurology (NY) 1982;32:1260-6.

${ }^{20}$ Gastaut H, Tassinari CA, Boweau-Pallas J. Polygraphic and clinical study of the epileptic atonic drops. Rev Neurol (Paris) 1966;36:5-21.

${ }^{21}$ Cirignotta F, Montagna P, Lugaresi E. Muscular inhibitory and excitatory phenomena during spike-and-wave 
discharges: effect of posture. J Neurol Neurosurg Psychiatry 1981;44:1172-3.

${ }^{22}$ Grinker RR, Serota H, Stein SI. Myoclonic epilepsy. Arch Neurol Psychiat 1938;40:968-80.

${ }^{23}$ Bancaud J. Physiopathogenesis of generalized epilepsies of organic nature (stereoencephalographic study) (chap. 14). In: Gastaut H, Jasper H, Bancaud J, Waltregny A, eds. The Physiopathogenesis of the Epilepsies. Springfield, Ill.: Charles C. Thomas, 1969: 158-85.

${ }^{24}$ Gloor P. Generalized epilepsy with spike-and-wave discharge: a reinterpretation of its electrographic and clinical manifestations. Epilepsia 1979;20:571-88.

${ }^{25}$ Dondey M. Transverse topographical analysis of petit mal discharges: diagnostic and pathogenic implications. Electroencephalogr Clin Neurophysiol 1983; 55:361-71.

${ }^{26}$ Jasper HH, Droogleever-Fortuyn J. Experimental studies of the functional anatomy of petit mal epilepsy. Res Publ Ass Nerv Ment Dis 1946;26:27298.

${ }^{27}$ Hubel DH, Nauta WJH. Electrocorticograms of cats with chronic lesions of the rostral mesencephalic tegmentum. Fed Proc 1960;19:287.

${ }^{28}$ Weir B. Spike-wave from stimulation of reticular core. Arch Neurol 1964;11:209-18.

${ }^{29}$ Cesa-Bianchi MG, Mancia M, Mutani R. Experimental epilepsy induced by cobalt powder in lower brainstem and thalamic structures. Electroencephalogr Clin Neurophysiol 1967;22:525-36.

${ }^{30}$ Rodin E, Onuma T, Wasson S, Porsak J, Rodin M. Neurophysiological mechanisms involved in grand mal seizures induced by metrazol and megimide. Electroencephalogr Clin Neurophysiol 1971;30:62-72.

${ }^{31}$ Zuckermann EG, Glaser GH. Urea-induced myoclonic seizures. Arch Neurol 1972;27:14-28.

${ }^{32}$ Velasco F, Velasco M, Romo R. Specific and nonspecific multiple unit activities during pentylenetetrazol seizures. I. Animals with "encephale isole".
Electroencephalogr Clin Neurophysiol 1980;49:6007.

${ }^{33}$ Stevens JR, Nakamura Y, Milstein V, Okuma P, Llinas $R$. Central and peripheral factors in epileptic discharge. Arch Neurol 1964;11:463-76.

${ }^{34}$ Morison RS, Dempsey EW. A study of thalamo-cortical relations. Am J Physiol 1942;135:281-92.

${ }^{35}$ Kostopoulos G. Potentiation and modification of recruiting responses precedes the appearance of spike and wave discharges in feline generalized penicillin epilepsy. Electroencephologr Clin Neurophysiol 1982;53:467-78.

${ }^{36}$ Spiro AJ. Minipolymyoclonus: a neglected sign in childhood spinal muscular atrophy. Neurology (Minneap) 1970;20:1124-6.

${ }^{37}$ Riggs JE, Gutmann L, Schochet SS. Contraction pseudotremor of chronic denervation. Arch Neurol 1983;40:518-9.

${ }^{38}$ Denny-Brown D, Pennybacker JB. Fibrillation and fasciculation in voluntary muscle. Brain 1938;61:31134.

${ }^{34}$ Symonds C. Myoclonus. Med J Austral 1954;21:765-8.

${ }^{40}$ VanHeycop Ten Ham MW, DeJager H. Progressive myoclonus epilepsy with Lafora bodies. Clinicalpathological features. Epilepsia 1963;4:95-119.

${ }^{41}$ Howell DA. Unusual centrencephalic seizure patterns. Brain 1955;78:199-208.

${ }^{42}$ Doose H, Gerken H, Leonhardt R, Volzke E, Volz C. Centrencephalic myoclonic-astatic petit mal. Neuropaediatrie 1970;2:59-78.

${ }^{43}$ Jankovic J, Fahn S. Physiologic and pathologic tremors. Ann Int Med 1980;93:460-5.

${ }^{44}$ Shahani BT, Young RR. Physiological and pharmacological aids in the differential diagnosis of tremor. $J$ Neurol Neurosurg Psychiatry 1976;39:772-83.

${ }^{45}$ Kinsbourne M. Myoclonic encephalopathy of infants. $J$ Neurol Neurosurg Psychiatry 1962;25:271-6.

${ }^{46}$ Dyken P, Kolar O. Dancing eyes, dancing feet: infantile polymyoclonia. Brain 1968;91:305-20. 